\title{
Laboratory Investigation of Sediment Transport under Transient Flow - Preliminary Results
}

\author{
Łukasz PRZYBOROWSKI ${ }^{1, \bowtie}$, Michael NONES ${ }^{1}$, Magdalena MROKOWSKA $^{1}$, \\ Leszek KSIĄŻEK ${ }^{2}$, PHAN Cong Ngoc $^{2}$, Andrzej STRUŻYŃSKI ${ }^{2}$, and Maciej WYRĘBEK ${ }^{2}$ \\ ${ }^{1}$ Institute of Geophysics, Polish Academy of Sciences, Warszawa, Poland \\ ${ }^{2}$ University of Agriculture in Kraków, Faculty of Environmental Engineering and Land Surveying, \\ Kraków, Poland \\ lprzyborowski@igf.edu.pl
}

\begin{abstract}
Flooding events in rivers are usually causing an increment in sediment transport. To investigate the relationships between bedload, bed shear stress and wave characteristics, laboratory experiments were performed in a 12-m-long flume at the University of Agriculture in Kraków, Poland. Three sets of experiments were conducted, imposing singular trapezoidal flood waves as forcing terms. The maximal wave height differed between runs, but the water volume and bed slope stayed the same. The bed was covered with mixed gravel, and the sediment was weighted using a trap at the end of the flume. The water level was measured at 5 points along the flume, while the velocity was measured in the middle of the flume by Acoustic Doppler Velocimeter at a point $7 \mathrm{~cm}$ above the bed. Preliminary results show that unsteadiness of flow induces the variation of bedload transport during the wave passage and that the total yield of sediment is positively correlated with the wave magnitude.
\end{abstract}

Keywords: ADV, laboratory experiments, sediment transport, unsteady flow.

\section{INTRODUCTION}

The studies of sediment transport in conditions most comparable to that of natural watercourses are essential in understanding the effects of naturally and accidentally occurring events. Such events are associated with abrupt unsteadiness of the river flow, which causes a higher rate at which sediments are moved within a river, resulting eventually in morphodynamic and water 
quality changes (Michalik and Książek 2009). Recent laboratory experiments correlated bed shear stress, bedload rate and stream power, and pointed out that hysteresis is present in the relationship between sediment flux and flow rate, as well as between other process variables (Mrokowska et al. 2018; Phillips et al. 2018). Moving from such findings, the present experiments were designed to further investigate the characteristics of transient flows, and the influence of wave characteristics on the bedload dynamics.

\section{EXPERIMENTAL SETUP}

Experiments were performed in 12-m-long and 0.485-m-wide flume. The channel bottom was covered with a layer of mixed gravel with median grain size $d_{50}=3.52 \mathrm{~mm}$ and maximal grain size $d_{\max }=12.50 \mathrm{~mm}$. Trapezoidal waves were generated varying the maximum discharge. Water depth was measured using 5 resistive sensors placed along the flume. The flow velocity was measured at a point around $7 \mathrm{~cm}$ above the bed, using a Sontek ADV at $50 \mathrm{~Hz}$ placed in the middle of the flume. Before each run, the bed was manually smoothed, and the flume was slowly filled with water, initially to discharge equal to $6 \mathrm{~m}^{3} / \mathrm{h}$, then for 2 minutes increased to $80 \mathrm{~m}^{3} / \mathrm{h}$, which was estimated to correspond to incipient motion conditions.

\section{RESULTS}

Three series of experiments were conducted and repeated, obtaining 10 runs in total with three different wave magnitude. Accordingly, the average water depth during a wave peak was $13.0 \mathrm{~cm}$ with average discharge $Q=176 \mathrm{~m}^{3} \mathrm{~h}^{-1}$ and stream power $\omega=2.34 \mathrm{Nm}^{-1} \mathrm{~s}^{-1}$ for the first set of tests; $11.9 \mathrm{~cm}$ with $Q=150 \mathrm{~m}^{3} \mathrm{~h}^{-1}$ and $\omega=2.91 \mathrm{Nm}^{-1} \mathrm{~s}^{-1}$ for the second; $9.6 \mathrm{~cm}$ with $Q=113 \mathrm{~m}^{3} \mathrm{~h}^{-1}$ and $\omega=1.49 \mathrm{Nm}^{-1} \mathrm{~s}^{-1}$ for the third test. The dimensionless shear stress derived from the ADV data exceeded the critical shields parameter. The bedload rate $q\left[\mathrm{kgs}^{-1}\right]$ was an order of magnitude higher during the highest discharge case (Fig. 1a) in comparison to the lowest discharge (Fig. 1b).

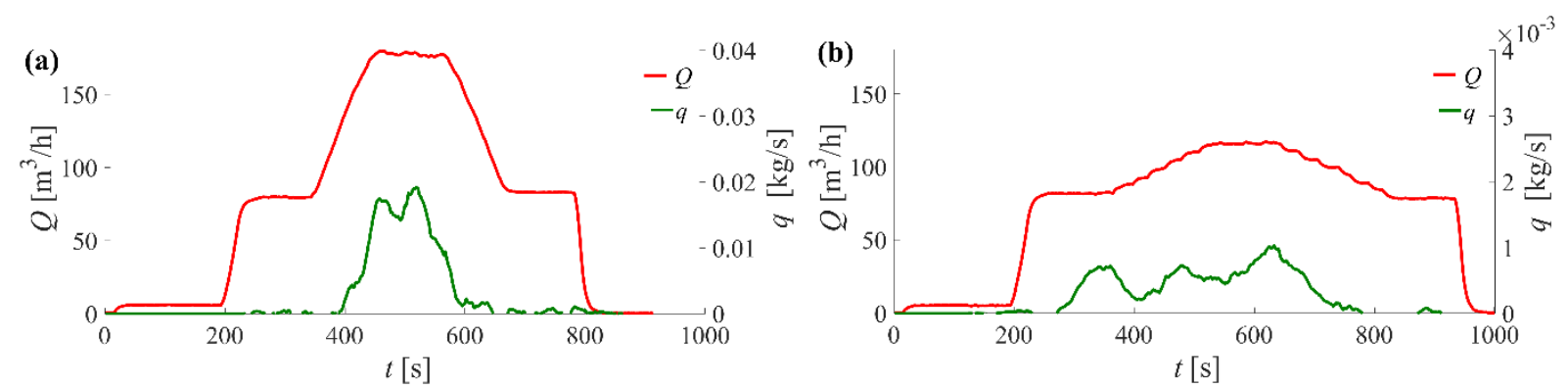

Fig. 1. Recorded hydrographs with discharge and bedload rate for a wave with a peak at: $180 \mathrm{~m}^{3} \mathrm{~h}^{-1}$ (a) and $115 \mathrm{~m}^{3} \mathrm{~h}^{-1}(\mathrm{~b})$.

Acknowledgements. We express our gratitude to Szymon Wojak who was actively engaged in the process of laboratory data collection.

\section{References}

Michalik, A., and L. Książek (2009), Dynamics of water flow on degraded sectors of Polish mountain stream channels, Pol. J. Environ. Stud. 18, 4, 665-672. 
Mrokowska, M.M., P.M. Rowiński, L. Książek, A. Strużyński, M. Wyrębek, and A. Radecki-Pawlik (2018), Laboratory studies on bedload transport under unsteady flow conditions, J. Hydrol. Hydromech. 66, 1, 23-31, DOI: 10.1515/johh-2017-0032.

Phillips, C.B., K.M. Hill, C. Paola, M.B. Singer, and D.J. Jerolmack (2018), Effect of flood hydrograph duration, magnitude, and shape on bed load transport dynamics, Geophys. Res. Lett. 45, 16, 8264-8271, DOI: 10.1029/2018GL078976.

Received 22 March 2021

Accepted 12 April 2021 